\title{
INTERVENÇÃO EM PREEXISTÊNCIA: CENTRO CULTURAL NA ANTIGA ESTAÇÃO FERROVIÁRIA DE SANTO ANASTÁCIO - SP
}

Fernanda de Almeida Vergani, Fabrícia Dias da Cunha de Moraes Fernandes Borges

Universidade do Oeste Paulista - UNOESTE. Curso de Arquitetura e Urbanismo, Presidente Prudente - SP. E-mail:

fer vergani@hotmail.com

\section{RESUMO}

O presente artigo trata-se da resultante da primeira parte do Trabalho de Conclusão de Curso desta autora, que abrange o embasamento teórico relacionado ao tema em questão, por meio da revisão bibliográfica de autores que já desenvolveram pesquisas na mesma área, para fundamentar teoricamente o projeto. O tema é a proposta de um Centro Cultural como espaço de cultura e lazer comunitário para a cidade de Santo Anastácio - SP, que carece deste tipo de atividade, pois não oferece um local para que todas as classes sociais usufruam das manifestações culturais. Será inserida na antiga estação ferroviária deste município, construída no ano de 1939, através de uma intervenção arquitetônica, com a reabilitação deste edifício preexistente, por ser um patrimônio histórico abandonado, que sem ser devidamente tratado, tende a ruir em curto espaço de tempo.

Palavras-chave: Centro Cultural, Classes Sociais, Intervenção, Reabilitação, Preexistência.

\section{INTERVENTION IN PREEXISTENCE: CULTURAL CENTER IN ANCIENT RAILWAY STATION OF SANTO ANASTÁCIO - SP}

\begin{abstract}
This article comes from result of first part of final paper by this authoress, which covers the theoretical background related to the subject matter, through the bibliographical review of authors that have developed research in the same area, to theoretically justify the project. The theme is the proposed of a Cultural Center as space for culture and community recreation for the city of Santo Anastácio - SP, which lacks this type of activity because it does not offer a place for all of social classes enjoy the cultural manifestations. Will be inserted in the old railway station of this city, built in 1939, through an architectural intervention, with the rehabilitation this preexisting building, to be an abandoned historical heritage, which without being properly treated, tends to crumble in short time.
\end{abstract}

Keywords: Cultural Center, Social Classes, Intervention, Rehabilitation, Preexistence. 


\section{INTRODUÇÃO}

A privatização da Companhia Ferroviária Paulista S.A. para a FEPASA, ocorreu de tal modo que os prédios antigamente usados para o embarque e desembarque de passageiros e cargas, se tornaram abandonados. No que diz respeito a patrimônio ferroviário, Pozzer (2006, p.06), é corrente a ideia de que com a decadência desse tipo de transporte, seus espaços deterioram-se, tendo estas áreas uma visibilidade negativa, com grandes espaços vazios e estruturas desativadas.

Allis (2006, p.74) diz que atualmente, "a cultura, situada principalmente no contexto urbano, tem-se tornado insumo econômico para a construção de 'produtos turísticos', os quais serão consumidos em forma de turismo cultural." As ferrovias, por uma série de razões, podem ser atreladas à atividade turística por sua capacidade de materializar momentos históricos das regiões onde se instalou. (ALLIS, 2006). Sabe-se que esta atividade em patrimônios é algo que pode ajudar a fazer com que estes edifícios não fiquem inutilizados, servindo como um atrativo turístico para o município. Ressalta Allis (2006, p.124),

(...) o patrimônio cultural ferroviário, é composto por toda a gama de construções e materiais remanescentes de outras épocas da ferrovia, que, com ou sem uso atualmente, despertam interesse de manutenção nos ambientes em que se materializam e prometem alguma exploração turística.

Motta (2000) e Choay (2001) trabalham a ideia de que o mundo contemporâneo parece utilizar-se do patrimônio histórico com uma espécie de "produto de mercado" a ser explorado pela chamada "indústria cultural", evocando nos monumentos um novo valor simbólico para sua valorização, voltado para interesses que muitas vezes imprimem um caráter cênico ao uso cotidiano do objeto e que baseia sua preservação apenas em uma homologia das suas funções originais.

Nas cidades, a localização de muitos dos edifícios ferroviários desativados em áreas centrais tornam sua transformação particularmente interessante para usos institucionais, comerciais, de serviços, etc., dada a sua primitiva característica como centro de convergência de pessoas. Em certas localidades faltam edifícios para esses fins, entretanto, as transformações têm sido feitas com êxito, com a parceria dos setores públicos, privados e associações beneficentes. (KÜHL, 1998).

Kühl (1998) afirmou que nas cidades de pequeno porte, ou no campo, foram inúmeros e bemsucedidos os casos de reconversão para os mais variados fins, tais como escolas, museus, centros esportivos, teatros, residências, bares, restaurantes, locais para venda, entre outros, e completou: 
O patrimônio industrial, nele incluído o ferroviário, é relevante pela sua forma, variedade, destinação e riqueza histórica. Os planos para a recuperação do patrimônio ferroviário, tanto das edificações quanto das linhas, não são, como poderiam parecer inicialmente, ingênuos, frívolos ou inviáveis, e têm-se concretizado com sucesso. (KÜHL, B. M., 1998, p.239).

O estudo de caso é sobre a antiga estação ferroviária de Santo Anastácio, acerca da reabilitação do edifício, construído no ano de 1939 e atualmente sem uso. Em seu conjunto arquitetônico há também um galpão que se encontra em mau estado de conservação, e se não for devidamente tratado, tende a ruir em curto espaço de tempo.

A intervenção no conjunto existente tem como objetivo resgatar e valorizar as características históricas de cada construção, através da restauração de seus elementos construtivos e da inserção de novos atributos relativos à mudança de uso. Os novos itens incorporados ao patrimônio serão característicos da contemporaneidade. Assim, reforçando a distinção entre a intervenção e a originalidade do conjunto.

Através da reabilitação, o estudo prevê um Centro Cultural como espaço de cultura e lazer comunitário, pois a cidade carece deste tipo de atividade, não oferecendo um local para que a população usufrua das manifestações culturais.

\section{METODOLOGIA}

A metodologia de pesquisa caracterizou-se por meio de estudos bibliográficos acerca dos conceitos que abordam o tema do trabalho, de forma a dar subsídios teóricos para a discussão, e através de análises de projetos arquitetônicos referentes. Posteriormente, foram feitas análises in loco com a finalidade de levantar as problemáticas e coletar dados do local suficientes para a elaboração do projeto.

Com base nos conceitos de Gil (2002) e Santos (2004), são apresentados os principais procedimentos para coleta e análise de dados: pesquisa bibliográfica; pesquisa documental; estudos de casos; estudo de campo.

$\mathrm{Na}$ coleta in loco, os materiais utilizados foram: procedimentos prévios, que são os levantamentos, as análises e as prospecções; um diagnóstico estático-construtivo e identificação de patologias; leitura histórico-crítica do bem; e a definição de diretrizes de intervenção. A principal ideia 
é obter uma informação prévia do imóvel e do seu estado de conservação para futuro desenvolvimento do projeto arquitetônico.

\section{RESULTADOS PRELIMINARES}

Tem como base na percepção do local, a presença de um observador que se relaciona com um espaço. Esta análise se objetiva em um levantamento gráfico do entorno do edifício da antiga Estação Ferroviária de Santo Anastácio - SP em uma escala setorial e o estudo dos fatores que configuram o local.

Como ferramenta para conduzir as análises foi utilizado o livro de Gordon Cullen, "Paisagem Urbana" (2008), que explica a relação do homem com o ambiente, as sensações, as relações visuais, os percursos e a visibilidade de um local. Esse estudo é muito importante para entender o contexto onde o edifício está inserido. Além dos percursos, uma leitura física em planta baixa da área foi também realizada.

Foi feita a leitura da área de intervenção, incluindo a percepção do local, sua análise morfológica, levantamento topográfico, condicionantes climáticas e a materialidade da preexistência e sua conservação; feito um pré-estudo da organização espacial do edifício antigo para a adequação do novo centro cultural, e de suas diferentes áreas de atividades que são construídas de acordo com suas especificidades; e foram averiguadas quais informações, dentre aquelas disseminadas pelo centro cultural, são mais acessadas e utilizadas pelos usuários do centro, voltado a todas as classes sociais.

\section{DISCUSSÃO}

Entende-se que a reabilitação será de grande importância para o edifício, uma vez que se trata da sistematização de um repertório de soluções que mostram algumas possibilidades de compatibilização entre sistemas construtivos e linguagens arquitetônicas diferentes (antiga e contemporânea), além das deficiências físicas, construtivas e funcionais, acumuladas ao longo dos anos no edifício antigo (estação ferroviária).

As edificações nas cidades representam todas as transformações ocorridas ao longo do tempo. Todas elas formam na paisagem urbana várias temporalidades juntas em um só lugar. Os edifícios históricos se relacionam com esse aspecto entre a época de sua construção e a época atual, tornando-se para os observadores um referencial de memória agregando valor a cidade. 
O avanço tecnológico no campo da engenharia, com grandes novidades nos métodos construtivos, tem aumentado a velocidade das novas construções, visando muitas vezes, apenas às necessidades e funções que o local deverá exercer. Esse novo modelo de arquitetura contemporânea, intervém nas edificações antigas, em grande parte, desconsiderando o existente e seu histórico, ou imitando o antigo, provocando um falso estético e histórico.

Considerar a edificação em todos os seus períodos, tanto na sua estética quanto em cada momento de sua história, é o que pretende ser realizado no edifício da antiga Estação Ferroviária de Santo Anastácio - SP, na concepção do desenvolvimento do projeto. Com isso, necessita-se estudar seu contexto urbano para que com as informações, a proposta esteja mais próxima da realidade do local que condiz com a área central da cidade e suas características.

\section{CONCLUSÃO}

Mediante ao diagnóstico realizado, seria o caso reabilitar o conjunto da antiga estação ferroviária de Santo Anastácio - SP, devido ao atual abandono do mesmo. Procura-se ao mesmo tempo uma modernização e uma beneficiação geral tanto para a população, inserindo neste lugar um novo Centro Cultural, quanto para o edifício em si - atualizando as suas instalações, equipamentos e a organização dos espaços existentes -, melhorando o seu desempenho funcional e tornando esse edifício apto para o seu completo e atualizado reuso.

Essas estruturas não podem ser esquecidas e deixadas de lado, pois pode ocorrer de pessoas sem teto e entorpecentes ocuparem o local abandonado. Deve-se preservar uma construção deste patamar, pois com ela temos um resgate histórico do município e com isso pode-se alimentar a cultura nessa localidade, uma vez que a mesma esteja preservada e com condições para a visitação.

Pode-se compreender que a restauração e a utilização da arquitetura de outra época, conforme descrito, é uma atividade viável. Portanto, esta deve ser aplicada de maneira correta, tomando os devidos cuidados, sempre preservando o patrimônio, mantendo sua identidade, e fazendo com que se mostre presente no cotidiano da sociedade, trazendo benefícios para a mesma.

\section{REFERÊNCIAS}

ALLIS, Thiago. Turismo, patrimônio cultural e transporte ferroviário. Um estudo sobre ferrovias turísticas no Brasil e na Argentina. São Paulo, 2006.

CHOAY, Françoise. A alegoria do patrimônio. São Paulo: Estação Liberdade / UNESP, 2001. 209 p. 
CULLEN, Gordon. Paisagem Urbana. Lisboa, 1a ed. Edições 70, 2008.

GIL, Antonio Carlos. Como elaborar projetos de pesquisa. 4ạ ed. São Paulo: Atlas, 2002. 175 p.

KÜHL, Beatriz M. Arquitetura do Ferro e Arquitetura Ferroviária em São Paulo: reflexões sobre a sua preservação. 1ạ ed. São Paulo: Ateliê Editorial, 1998. V. 1, 438 p.

MOTTA, Lia. A apropriação do patrimônio urbano: do estético-estilístico nacional ao consumo visual global. Campinas: Papirus, 2000. 259 p.

POZZER, Guilherme P. Arqueologia e Patrimônio Industrial: a Estação Cultura em Campinas. Campinas, 2006.

SANTOS, Antonio Raimundo dos. Metodologia científica: a construção do conhecimento. 6a ed. Rio de Janeiro: DP\&A, 2004. 144 p. 